\title{
A EFICÁCIA DO MARKETING COMO VANTAGEM COMPETITIVA: ESTUDO DE CASO POSTOS DE COMBUSTÍVEIS
}

\section{THE EFFECTIVENESS OF MARKETING AS A COMPETITIVE ADVANTAGE: FUEL-POST CASE STUDY}

\author{
Vanessa Lima Silva ${ }^{1}$; Antonio Carlos Estender ${ }^{2}$
}

\section{RESUMO:}

O objetivo deste artigo é abordar as estratégias de marketing, auxiliando das projeções de vendas no ramo de combustíveis. Exibe o aperfeiçoamento de um modelo teórico de formação da estratégia de marketing e seu auxilio para a vantagem competitiva. Para isso, analisou-se a literatura sobre estratégia e utilizou-se alguns modelos de formação da estratégia de marketing. Juntamente a esses modelos, associou-se uma pesquisa exploratória efetuada na organização tratada no presente, a qual permitiu que fosse criada um plano de ações para solucionar as variáveis que prejudicavam as vendas do produto ofertado. A análise dos resultados da pesquisa propõe indicadores consideráveis, para a construção da estratégia de marketing. Esse modelo colabora com o estudo da estratégia de marketing por demonstrar reflexões sobre formulação e implementação de estratégias, formando uma vantagem a partir das várias visões de estratégia.

PALAVRAS-CHAVE: Estratégia. Vendas. Diferenciação. Mix de marketing.

\section{ABSTRACT:}

The objective of this article is to approach the marketing strategies, focusing on assisting sales projections in the field of fuels. It shows the improvement of a theoretical model of marketing strategy formation and its aid to the competitive advantage. For this, the strategy literature was analyzed and some models of marketing strategy formation were used. Together with these models, an exploratory research was carried out in the organization treated in the present, which allowed the creation of a plan of actions to solve the variables that harmed the sales of the offered product. The analysis of the results of the research proposes considerable indicators for the construction of the marketing strategy. This model collaborates with the study of the marketing strategy by showing reflexions about strategy formulation and implementation, forming an advantage from the various strategic visions.

KEYWORDS: Strategy. Sales. Differentiation. Marketing mix.

1 Bacharel em Administração pela Universidade UNG

2 Mestre em Administração e professor da Estácio de Sá 


\section{INTRODUÇÃO}

Muitos estudiosos vêm trazendo à visão administrativa, alguns requisitos importantes na hora de coordenar e ordenar uma organização. Diante da fragilidade do mercado é possível enxergar a dificuldade dos estabelecimentos em manter uma imagem progressiva de qualidade e diferencial, por conta de concorrentes cada vez mais atrativos e, a eficácia de marketing vem como uma vantagem competitiva auxiliando no momento das tomadas de decisões, direcionando o administrador conforme os requisitos avaliados para que possa se destacar perante os demais concorrentes, se tornando assim uma empresa diferenciada.

Hooley, Saunders e Piercy (2005); Zeithaml, (2014), vêm analisando o objeto de pesquisa, conforme apontado na revisão de literatura, em seus diferentes níveis de entendimento e aplicação ao contexto organizacional. Pode-se encontrar na literatura definições para estratégias de marketing; e marketing como vantagem competitiva (HOOLEY, SAUNDERS e PIERCY, 2005), o que demanda a construção de um modelo teórico/empírico/gerencial que explicite como estes diferentes conceitos se articulam e podem contribuir para o entendimento de propostas para o desenvolvimento organizacional.

A rede de postos relacionada pelo presente encontra oscilações nas vendas de combustíveis da mesma região, onde um posto vende mais do que o outro, causando assim uma diferença econômica muito grande, resultando em prejuízos, pois um precisa cobrir as dívidas do outro. Diante a situação atual foi então criada o questionamento de porquê o marketing pode se tornar uma ferramenta de vantagem competitiva? Quais os benefícios ao utilizar o marketing para se obter vantagem competitiva?

Para isso, é preciso entender quais as soluções possíveis para alavancar as vendas e, destacar a diferenciação da organização em meio ao ambiente no qual atua. No estudo levantado, será nítido ver que a deficiência na área de marketing de uma rede de postos de combustíveis pode resultar em um declínio no rendimento financeiro, atingindo assim diretamente seus resultados. Entretanto, com as análises estudadas, será possível utilizar das ferramentas de marketing como uma vantagem competitiva, e mos- trar que toda organização pode ser rentável mesmo diante as inúmeras barreiras de mercado.

Este trabalho tem por objetivo verificar a relação da eficácia do Marketing para alcançar vantagem competitiva. Para isso será preciso analisar melhor os clientes que frequentam os postos, apontando suas preferencias em relação ao produto, praça, preço e promoção, avaliar o nicho e a concorrência, criando novos pontos estratégicos e sintetizar a prestação de serviços através de atendimento, qualidade e transparência.

Agora será possível saber o que exatamente os clientes estão à procura, e o quanto estão dispostos a pagar por um produto que é facilmente encontrado no concorrente. A maioria das pessoas, procuram por algo mais em conta e que de certa forma não vá prejudica-las. Tratando-se de combustível é importante destacar a sua qualidade, e com um preço justo pode ser muito bem aceito, apesar de não poder fugir da média de preço encontrada no mercado, será preciso manter equilibrado as duas vertentes.

Uma vez que existe uma sintonia entre cliente, preço e produto podemos então chegar aos indicadores necessários para um bom rendimento econômico e fatalmente um crescimento considerável.

O presente estudo visa a contribuir para a elucidação de questões relacionadas ao objeto de pesquisa. Almeja-se preencher a lacuna empírica/gerencial identificada na relação entre estratégias de marketing; vantagem competitiva A contribuição mais relevante é de natureza empírica/ gerencial, pois durante a realização da pesquisa, constatou-se a necessidade de estudos relacionados ao objeto de pesquisa, para assim gerenciar as metas e objetivos definidos pela organização, desta forma é possível contribuir para a melhora do ambiente organizacional.

Para o desenvolvimento da pesquisa, em termos metodológicos, será adotada a abordagem qualitativa. Para Collis e Hussey (2005), em relação aos procedimentos serão realizadas entrevistas. As pesquisas deste tipo se caracterizam pela interrogação direta das pessoas cuja percepção se deseja conhecer. Basicamente, procede-se à solicitação de informações via questionários a um grupo de stakeholders acerca do questionamento/problema estudado para em seguida, mediante análise, obter as conclusões corresponden- 
tes aos dados coletados. A população entrevistada foi de 25 pessoas de diferentes hierarquias e as amostras foram analisadas de forma empírica.

\section{REVISÃO DE LITERATURA}

\subsection{Estratégia de Marketing e a Vantagem Competitiva}

De acordo com Greene (1986), os riscos de marketing que levam a redução de lucro estão ligados as incertezas e o involuntário, e ignora-lo pode ser um sinal de risco, ou seja, não ter o planejamento de um cenário otimista, pessimista e provável que normalmente é utilizado como uma ferramenta de vantagem competitiva pode trazer grandes surpresas que não são favoráveis a um estabelecimento, independentemente de seu ramo de atuação. Se preparar para os possíveis acontecimentos do ambiente externo, traz a organização os requisitos necessários para o embarque de novas possibilidades, podendo encara-las frente a frente, sem medo e com o máximo de convicção possível.

Manter a fidelização do cliente ao negócio é um detalhe muitas vezes esquecidos pelos administradores, sabendo-se que um cliente fiel, será uma venda pré-concretizada. Newton (1986), vai dizer que a responsabilidade básica de vendas técnicas, para uma boa vantagem competitiva é de aumentar o faturamento da empresa junto aos clientes já existentes. Uma vez que estiver satisfeito, poderá voltar diversas vezes e, divulgar o estabelecimento para pessoas de seu convívio, sendo assim, será possível enxergar uma linha de progressão de vendas sem delimitações. O foco é manter o que se tem, e aos poucos ganhar uma zona maior de clientes em volta do estabelecimento.

Segundo Churchill Jr e Peter (2000) é uma regra geral, o preço do produto ser suficientemente alto para cobrir o custo e o marketing; na teoria, é hábil acreditar que os preços poderão ser altos o suficiente para cobrir os custos e todo o marketing do produto, porém é preciso saber se o cliente estará disposto a pagar o valor pré-determinado, caso ao contrário, será em vão precificar o produto, uma vez que esse mesmo cliente se renegue a pagar não será possível alcançar os objetivos estabelecidos. Por isso, será necessária toda uma projeção de vantagem competitiva, para poder incrementar a teoria de Peter.

Construir uma vantagem competitiva sustentável será primordial para um diferencial estratégico, para isso é preciso utilizar os recursos existentes ou até mesmo cria-los, sendo estes a cultura organizacional, ativos de marketing e capacidade de marketing. Sabendo-se que toda empresa terá uma longa lista de recursos, deve-se saber que alguns serão mais utilizados do que os outros. Segundo Hooley, Saunders e Piercy (2005), na teoria de dependência de recursos (TDR) traz algumas características de vantagens competitivas, que gera valor para os clientes; um recurso de exclusividade rara da empresa; e o recurso que os concorrentes não conseguem imitar.

Nessa mesma linha de raciocínio Hooley, Saunders e Piercy (2005) vão dizer que a diferenciação na vantagem competitiva é um fator extremamente importante para construir uma posição de mercado, onde os funcionários da empresa podem ser o recurso mais relevante para gerar a diferenciação. Sendo assim, qualquer empresa que não levar em consideração a força do trabalho eficaz das pessoas, pode estar deixando sua competitividade inferior à de uma outra empresa que utiliza dessa ideia, ou seja, a maior diferenciação não está em quem cria as estratégias, e sim naqueles que a executam da melhor maneira possível.

A respeito do endomarketing como uma ponta das vantagens competitivas, podendo-se considerar as orientações de marketing interno; os tipos de práticas; como o marketing pode ser planejado como parte da estratégia competitiva e unificação de demais áreas das organizações para melhor aplica-la. Hooley, Saunders e Piercy (2005) mostram que focar também nos clientes, concorrentes e mercado é um de seus fundamentos e, trazem uma consistência maior as estratégias pois juntos, existe um equilíbrio entre ambiente interno e externo da organização.

O intuito de uma boa vantagem competitiva, vai dizer que o marketing opera em dois principais niveis organizacionais: o estratégico e operacional Segundo Hooley, Saunders e Piercy (2005), no nivel operacional os gerentes de markerting e de marca lidam com as tarefas do dia-a-dia, enquanto no nivel estratégi- 
co o marketing atua como um auxiliar nas tomadas de decisões no mercado do qual está competindo. $O$ intuito principal é deixar o cliente em primeiro plano, usando os conhecimentos e habilidades, criando vantagem competitiva através de competência.

Porém Kotler e Keller (2006) dizem que marketing é um processo social onde as pessoas ou entidades adquirem aquilo que precisam através da criação, oferta, e livre negociação de valor com outros. Ou seja, criar um novo produto/serviço é o primeiro passo para adquirir novas perspectivas de clientes, numa mesma sequência, deve-se ofertá-lo e negociá-lo no mercado. O próximo passo para desenvolver as estratégias de marketing e vantagem competitiva é desenvolver esses aspectos, e elevar a um nível mais estratégico, onde seus resultados serão transformados em novas receitas. Ter em seus objetivos vínculo com a visão da organização ajuda a estabelecer esses indicadores que futuramente serão necessários para os fins de todo um projeto.

Segundo Magalhães e Sampaio (2007) falam que marketing é conhecer, decidir e agir. Podendo-se então entender que o marketing é uma estratégia de vantagem competitiva empresarial que otimiza os lucros, sua visão é entender melhor o seu público-alvo para posteriormente ofertar o seu tão esperado produto/serviço. Já as decisões e ações estão ligadas à parte estratégica da organização, uma vez que oferece o suporte para as tomadas de decisões. Todo o perfil de marketing está voltado a imagem que a empresa transpassa em relação aos seus produtos/ serviços, focado nos clientes e colaboradores.

O ponto ou praça como é conhecido popularmente seria o ambiente no qual ele está sendo oferecido e a promoção basicamente é a estratégia de vantagem competitiva utilizada na divulgação destes itens. Sendo assim, conhecidos como Mix de marketing, que tem um papel essencial no meio das organizações, pois ambas trabalhando em conjunto, oferecem inúmeros benefícios. Segundo Silva e Batalha (2007), os 4P's podem ser divididos em produto, preço, ponto de distribuição/vendas e promoção. Isto é, produto seria todo o bem/serviço ofertado, já o preço é todo o provento recebido pela oferta desses bens e serviços.

As estratégias competitivas podem ser dividi- das em dois grupos, sendo o primeiro baseado na diferenciação que visa o produto na perspectiva do cliente e, o segundo seria o escopo, buscando focar no mercado atendido, atendendo a perspectiva do fornecedor. De acordo com Mintzberg (2009), ambas as partes buscam diferenciar o produto/serviço da concorrência, sendo exclusivamente atencioso nos requisitos de imagem e qualidade. Nesse caso o conjunto de estratégia busca identificar na empresa, qual mercado ela deve participar segundo a visão de seus colaboradores. Pois a fatia de mercado do qual exercerá sua atuação irá contar como um indicador de potencial, uma vez que ser diferente dos concorrentes alavanca inúmeras possibilidades.

Levar em consideração os preços da concorrência, faz parte da estratégia de vantagem competitiva da empresa, uma vez que os preços fazem parte do Mix de marketing, ambas devem ser ligadas em prol do diferencial estratégico. Las Casas (2009), vai argumentar que para isso, um bom marqueteiro precisa não somente se conhecer, mas também conhecer o campo de batalha no qual está atuando, isso inclui os concorrentes, é certo que não tem como vencê-los sem nem ao menos saber o que ou por quanto estão oferecendo seus produtos, pois ter uma determinação nos preços fará com que a empresa lucre e alcance todos os resultados.

Segundo Kowalkowski (2011), vai dizer que o valor estabelece algumas vantagens competitivas juntamente com os clientes e colaboradores. Sem dúvidas esse valor retratado seria o processo relacional entre o produto oferecido e cliente, ou seja, o valor é algo subjetivo. Não quer dizer necessariamente que seia adotado através de indicadores de qualidade, capaz de ser medido. Seria então estabelecido por aqueles que consomem o produto, isso mostra o quanto o marketing tem uma relação direta com o valor, tendo em suas mãos a capacidade de auxiliar os colaboradores a entender todo o contexto de tal conjuntura.

Uma empresa que procura uma "posição de alta qualidade" tem que estar disposta a produzir com alta qualidade, ter preços altos, garantir a alta qualidade do produto fornecido e também fazer sua propagação através de mídias de alta qualidade, sendo assim Santiago (2012), enfatiza que a única forma de 
construir uma posição lógica de qualidade, faz com que até os mínimos detalhes sejam levados em consideração para obter uma estratégia consolidadora. Juntamente com as estratégias de marketing, tais táticas podem ser alcançadas, bastando somente uma estruturação propicia de vantagem competitiva.

Mix de marketing, pode ser usado como uma ferramenta de vantagem competitiva e, através deste é possível oferecer um bom preço de acordo com o produto ofertado, estabilizar a localidade do negócio em uma área estrategicamente analisada, barganhar os valores com fornecedores e, inserir novos produtos ao mercado, fazem o Mix de marketing girar de uma forma plena e satisfatória. Segundo Zeithaml, (2014), vai dizer que o conceito básico de marketing envolve o seu Mix de marketing, que são os elementos controlados e utilizados por uma organização para atender e comunicar-se com os clientes. Lógico que tudo depende da reação do cliente em relação aos temas abordados, nem sempre os resultados serão positivos, assim podendo sofrer algumas alterações no decorrer dos processos, uma vez que as vendas não atingir seus indicadores estipulados.

Necessitar de um produto, vem através do desejo e, segundo o dicionário Michaelis (2014), essa palavra mostra o impulso do cliente em relação as suas vontades, podendo ser drasticamente explorada pelas organizações a fim de usar esse anseio a seu favor, sendo assim é possível entender que o comportamento humano deve ser colocado em pauta pois será essencial para fazer as estratégias de marketing e mapear as vantagens competitivas através deste. Alves, Barboza e Rolon (2014), ressaltam que o marketing e suas estratégias têm que começar antes da produção de um bem ou serviço, através das necessidades do seu público-alvo. Isso mostra o quanto é importante trabalhar uma estratégia eficaz de marketing, antes mesmo de colocar um produto/ serviço em mercado.

\section{ESTRATÉGIAS DE PESQUISA}

Esta seção trata das estratégias de pesquisa que foram adotadas para a realização da pesquisa, de acordo com os objetivos propostos. Na metodologia foi utilizada pesquisa de campo, com abordagem qualitativa e como técnica de pesquisa, entrevistas.

E para atingir os objetivos propostos, delineou-se uma pesquisa de caráter exploratório e descritivo. O estudo de caráter exploratório busca o entendimento do fenômeno na sua complexidade, (GIL, 2002), a pesquisa exploratória deve proporcionar maior familiaridade com o fenômeno ao envolver técnicas específicas, como por exemplo, o levantamento bibliográfico. Respeitando esta abordagem e seu caráter exploratório, o estudo contempla a revisão da literatura estratégias de marketing, de acordo com ALMEIDA (2011), a pesquisa exploratória tem a finalidade de buscar relações entre conceitos, características e ideias.

Já na pesquisa descritiva se realiza o estudo, registro e interpretação dos fatos do mundo físico sem a interferência do pesquisador. Nesse tipo, após a coleta de dados é feita uma análise da empresa, sistema de produção ou produto, por isso também pode ser entendida como um estudo de caso (CERVO, 2007).

$\mathrm{O}$ estudo de caso refere-se a rede de postos de combustíveis JPS. Para esse estudo, foi levada em consideração as estratégias de marketing adotadas pela empresa e suas vantagens em relação ao mercado. Existiu então entrevistas com 14 funcionários de níveis hierárquicos diferentes, sendo estes: Gerentes, supervisores, auxiliares e atendentes e, cerca de 11 clientes próximos da região, utilizando uma entrevista interrogatório onde era possível que expressassem sua opinião de acordo com o problema na diminuição de vendas de combustíveis, para melhor compreender e opinar sobre as possíveis causas e efeitos da mesma. O papel do marketing na rede JPS tem ocupado um espaço pequeno, e sua eficácia acaba sendo prejudicada, pois erradica a vantagem competitiva, uma vez que as estratégias não são colocadas em pauta. No decorrer do estudo, foram analisados os postos de combustíveis dos quais enfrentavam uma venda menor, com relação aos outros da mesma região, apesar de vários fatores serem apontados como causadores, alguns foram mais destacados, de acordo com os colaboradores mais próximos a empresa.

A Rede JPS é uma empresa nacional fundada em 2004, pela sociedade de dois irmãos que começaram com apenas um posto e, recentemente inau- 
gurou a $22^{\mathrm{a}}$ unidade na região do interior de São Paulo, contendo também alguns postos em cidades pequenas no estado de Minas Gerais, já a sede da organização se encontra em Guarulhos-SP na avenida Paulo Faccini. Atualmente o problema de maior índice foi localizado na cidade de Ribeirão-SP em três postos de diferentes pontos, sendo um no centro e os demais em bairros comuns. No local do problema fazem parte da equipe 3 gerentes, 18 frentistas. As vendas de um ponto a outro são drasticamente diferentes, e tendo em vista a situação atual de declínio, surgiu o ponto para o qual se refere este artigo, o que necessariamente os clientes estão à procura, e como usar as estratégias de marketing como um diferencial. Com base no problema, foi possível fazer um levantamento das necessidades ocorrentes no posto e, com foco no aperfeiçoamento nesse ramo de atuação, sendo estas: Melhorias em relação ao relacionamento com o cliente; Qualidade no produto ofertado; Localização acertada; Preços acessíveis a população envolvida.

Quanto à abordagem da pesquisa, foi utilizada a qualitativa, que é um meio para explorar e entender o significado que os indivíduos ou grupos atribuem a um problema social ou humano. O processo de pesquisa envolve o questionamento e os procedimentos que emergem dos dados coletados no ambiente do entrevistado, a análise dos dados é indutivamente construída a partir das particularidades para os temas gerais e as interpretações feitas pelo pesquisador acerca dos significados dos dados (CRESWELL, 2010).

A pesquisa qualitativa explora o conjunto de opi- niões, que neste estudo busca avaliar e estruturar a empresa, de uma forma que contribuam com a vantagem competitiva baseada nas estratégias.

Quanto aos procedimentos, a pesquisa configura-se como estudo de campo. A pesquisa de campo, conforme Filho (1998), é aquela em que o pesquisador deverá fazer uma coleta de dados, mas como o universo é grande demais, impossibilita uma coleta total. Esta será feita a partir de uma amostra, determinada cientificamente. Essa forma de consulta pode se dar por meio de questionário, entrevistas junto aos envolvidos, as entrevistas para esse trabalho foram realizadas individualmente no local de trabalho, com stakeholders de diferentes níveis hierárquicos. Alguns dos entrevistados concederam mais de um depoimento, colaborando significativamente com a pesquisa, permitindo a análise e considerações, de acordo com objetivos previamente estabelecidos. Essa pesquisa tem como base observar as vendas que ocorrem de uma região a outra identificando os fatores que ocasionam essas oscilações.

Quanto às técnicas, referem-se aos procedimentos que foram utilizados para coletar os dados empíricos durante a realização da pesquisa, além da observação direta, por meio das técnicas de observação, na qual a coleta é realizada utilizando-se de sentidos e significados construídos pelo pesquisador em relação a determinados aspectos da realidade observada. A coleta de dados foi realizada durante o mês de (outubro) de 2017, por meio de entrevistas, orientadas por um roteiro semiestruturado que foi constituído a partir dos objetivos propostos. 


\section{RESULTADOS E DISCUSSÕES}

Quadro 1: analisar as Prospecções acerca da relação entre o Marketing e a Vantagem competitiva

\begin{tabular}{|c|c|c|}
\hline Entrevistados & Dados da pesquisa & Soluções \\
\hline $\begin{array}{l}\text { Gerência } \\
\text { Assistente } \\
\text { Coordenadores } \\
\text { (6) }\end{array}$ & $\begin{array}{l}\text { De acordo com a gerência, marketing seria um } \\
\text { conjunto de elementos e técnicas voltadas a imagem } \\
\text { transmitida aos clientes; estratégias, no entanto são } \\
\text { os planos de ações a serem colocadas em práticas } \\
\text { para atingir os objetivos determinados pela empresa. } \\
\text { Em prol desse assertivo, fala-se que o problema nas } \\
\text { diminuições de vendas de combustíveis está ligado } \\
\text { ao mal atendimento ao cliente, pois uma pessoa que } \\
\text { não tem uma recepção adequada estaria sujeita a não } \\
\text { voltar mais e assim transmitir as pessoas ao seu redor } \\
\text { informações que não levassem estar consumindo o } \\
\text { produto também. A localização desvantajosa seria } \\
\text { um ponto negativo a esse fator, enquanto um posto } \\
\text { encontra-se em uma área central de fácil acesso, outro } \\
\text { é encontrado em bairros de difícil acesso. }\end{array}$ & $\begin{array}{l}\text { O primeiro aspecto a ser resolvido seria o de } \\
\text { investimento no agente humano, ou seja, } \\
\text { utilizar o desenvolvimento social para obter } \\
\text { melhor retorno não somente financeiro, } \\
\text { mas também a tudo que se refere ao clima } \\
\text { organizacional e relacionamento de cliente } \\
\text { e empresa. Outro fator para algumas } \\
\text { melhorias seria a capacitação de pessoas } \\
\text { através de treinamentos especificados e } \\
\text { voltados a atendimento, para futuramente } \\
\text { resolver as reclamações que ocorrem } \\
\text { posteriores ás vendas. }\end{array}$ \\
\hline $\begin{array}{l}\text { Colaboradores } \\
\text { Auxiliares } \\
\text { Atendentes (8) }\end{array}$ & $\begin{array}{l}\text { Os colaboradores, auxiliares de escritório e atendentes } \\
\text { vão descrever marketing como fonte de divulgação } \\
\text { e agregação de valor a sua marca ou produto } \\
\text { com o objetivo de atender as necessidades dos } \\
\text { clientes através do produto/serviço oferecido. Já a } \\
\text { estratégia seria o plano utilizado para atingir as metas } \\
\text { estabelecidas, firmadas através de um objetivo inicial. } \\
\text { Com tudo, o problema apontado se deve a imagem } \\
\text { que a empresa transmite a seus clientes, sendo uma } \\
\text { empresa que preza a integridade, em relação a fatores } \\
\text { como a garantia de que existe qualidade no produto é } \\
\text { realmente propagada e, se o atendimento ao cliente } \\
\text { será feito de forma que transpareça essa excelência. } \\
\text { Ao todo vai mostrar como seria a relação entre cliente } \\
\text { e atendente, ou seja, os funcionários atendentes } \\
\text { precisam transmitir os objetivos da empresa ao } \\
\text { cliente através de sua conduta, sendo cautelosos e } \\
\text { promissores na hora de falar e agir. }\end{array}$ & $\begin{array}{l}\text { A primeira solução sugerida seria verificar } \\
\text { a fonte fornecedora de combustíveis e } \\
\text { analisar seu produto, antes de comprá- } \\
\text { lo. Pois muitos clientes não sabem a } \\
\text { origem do produto ofertado e, na maioria } \\
\text { das vezes acaba causando uma certa } \\
\text { insegurança a quem está prestes a } \\
\text { abastecer seu veículo, inibindo assim } \\
\text { futuras possibilidades de venda. Por isso } \\
\text { expor selos de qualidade seria essencial } \\
\text { para essa resolução. Logo após o próximo } \\
\text { passo seria fazer divulgações por conta do } \\
\text { produto de qualidade oferecido, obtendo } \\
\text { uma carteira maior de clientes. Próximo } \\
\text { ponto seria melhorar o atendimento } \\
\text { através de pesquisa de satisfação, com } \\
\text { uma gratificação simbólica aos atendentes } \\
\text { melhor avaliado. }\end{array}$ \\
\hline
\end{tabular}




\begin{tabular}{|c|c|c|}
\hline VISTA & \multicolumn{2}{|c|}{$\begin{array}{l}\text { A EFICÁCIA DO MARKETING COMO VANTAGEM COMPETITIVA: ESTUDO DE CASO POSTOS DE } \\
\text { COMBUSTIVEIS } \\
\text { Vanessa Lima Silva; Antonio Carlos Estender }\end{array}$} \\
\hline Clientes (11) & $\begin{array}{l}\text { Na perspectiva dos clientes marketing é o processo } \\
\text { usado para determinar quais produtos ou serviços } \\
\text { possam interessar aos consumidores, sendo um tipo de } \\
\text { meio para a divulgação do mesmo e, estratégia seria } \\
\text { o plano utilizado para alcançar algum objetivo que a } \\
\text { organização gostaria de alcançar. De acordo com os } \\
\text { dados levantados o maior ponto crítico indicado para } \\
\text { a diminuição no consumo de combustíveis, seria o } \\
\text { alto preço, má qualidade do produto e o atendimento. } \\
\text { Variáveis que desfavorecem uma organização quando } \\
\text { mal utilizadas. Em relação ao preço, os consumos } \\
\text { podem diminuir por este mesmo estar acima em relação } \\
\text { ao dos concorrentes, existindo uma ligação direta com } \\
\text { o tipo de produto e se ele está sendo oferecido com } \\
\text { qualidade, se não há adulteraçães em sua composição. } \\
\text { A maioria dos postos destacados pelos clientes aponta } \\
\text { um certo nível de satisfação, e por esse motivo os levam } \\
\text { a buscar muita das vezes o produto mais longe, só para } \\
\text { garantir a propriedade do produto. }\end{array}$ & $\begin{array}{l}\text { A solução mais acertada de acordo com } \\
\text { os clientes seria oferecer um produto de } \\
\text { qualidade, com um preço acessível para } \\
\text { ganhar a confiança do mesmo. Oferecer } \\
\text { algo adequado aos veículos para não serem } \\
\text { prejudicados por danos causados através } \\
\text { do produto de má qualidade. Também foi } \\
\text { sugerido a capacitação dos funcionários } \\
\text { na hora de fazer o atendimento, visando a } \\
\text { educação e cordialidade, pois apontaram } \\
\text { um grande desafeto por parte desses } \\
\text { atendentes na hora em que se aproxima do } \\
\text { cliente para atender. Por fim, apontou-se } \\
\text { também que o preço deveria ser reajustado } \\
\text { a um valor mais acessível ao bolso do } \\
\text { consumidor, pois com os aumentos as } \\
\text { pessoas buscam meios alternativos para se } \\
\text { locomover de forma que será mais benéfico, } \\
\text { sendo esses ônibus, avião e dependendo } \\
\text { da distância, até mesmo bicicletas seriam } \\
\text { mais utilizadas. }\end{array}$ \\
\hline
\end{tabular}

Fonte: JPS (Rede de postos de combustíveis JPS)

Diante as informações adquiridas notam-se que cada grupo de entrevistados tem uma perspectiva a respeito de marketing e estratégia competitiva. Cada um desses expos as soluções voltadas para o produto, atendimento e qualificação pessoal.

Em relação as convergências, pode-se identificar que todos os entrevistados nos três pontos de vistas visaram a qualidade no atendimento e fator humano como uma prioridade a ser solucionada. O público em si busca por atendentes que tenham maior atenção, quando estão no momento da compra, pois, o psicológico desse individuo vai comprovar que o estabelecimento cumpre com a imagem colocada em mercado, assim criando um vínculo de confiança entre comprador e estabelecimento. Outro fator encontrado entre clientes e colaboradores foi a qualidade do produto, visto que o principal produto oferecido é o combustível, o mesmo deve ser tratado com priorização na hora da compra e venda. Priorizar fornecedores que garantem selo de qualidade, é um fator que necessariamente deve ser colocado em pauta, pois de acordo com a agência nacional de petróleo (ANP), determina que o combustível, no caso, a gasolina, deve ter limites específicos de solventes e álcool misturados em sua composição e quais foram os fornecedores desse material.

Por isso o cliente é cada vez mais exigente so- bre o produto ao qual está consumindo, através das informações encontradas em fontes conhecidas e de fácil acesso. Mais um fator a ser colocado em pauta é o preço a qual esses combustíveis são colocados em mercado, que na realidade vem aumentando constantemente, e o público acaba fazendo pesquisas em relação à concorrência antes de efetuar a compra. Pode-se dizer então, que o valor ofertado, não pode estar muito diferente dos concorrentes, porém é necessário apontar maiores benefícios que levem o comprador a optar por aquele ponto de venda, sempre que estiver necessitando.

Com a relação as divergências percebem-se que a gerência irá enfatizar apenas o fator humano como priorização de soluções da problemática, diferente dos colaboradores e clientes que mostraram outros pontos específicos, sendo esses a qualidade e preço justo. A solução da gerência seria treinar os funcionários através de sua capacitação pessoal, utilizando daquilo que se tem, para posteriormente melhorar o que terá futuramente e assim alcançar os objetivos estabelecidos, que no caso não seria apenas o fator financeiro, mas também o clima organizacional e o valor agregado do serviço ao produto.

De acordo com os dados constantes no quadro 1, observou-se que as percepções dos stakeholders que responderam o questionário demonstrando o de- 
clínio de vendas em uma determinada região e a dissertação das soluções para melhorá-las. Para Mintzberg (2009), a imagem transmitida ao cliente pode alavancar inúmeras possibilidades, como o aumento na procura por um produto/serviço cada vez mais diferenciado, chegando próximo de seus objetivos.

Eliminar as variáveis que causam o problema é o primeiro passo para se chegar ao sucesso. Inicialmente existiria o investimento no capital humano, ou seja, seria necessária uma capacitação de pessoal com um treinamento adequado, levando em consideração o atendimento ao cliente como fator principal. Utilizar de uma pesquisa de satisfação, com questionários sobre como o cliente está sendo tratado para que através desses resultados possa ser encontrado os pontos certos de melhoria. Kowalkowski (2011) vai dizer que o valor de uma mercadoria é basicamente subjetivo, pois é criado com o tempo, através da conduta transmitida pelos colaboradores e qualidade do produto oferecido. Pode-se entender que um cliente satisfeito, agrega muito mais valor a uma organização do que um não satisfeito. Ter uma diferenciação na vantagem competitiva é um elemento indispensável para a construção de valor no mercado. Hooley, Saunders e Piercy (2005) enfatizam essa ideia dizendo que os funcionários da empresa podem ser o recurso mais relevante para gerar a diferenciação, por isso somente criar essas vantagens pode ser ineficaz quando não executadas pois não levar em consideração a força do trabalho eficaz das pessoas, pode deixar sua competitividade inferior à de uma outra empresa que utiliza dessa ideia.

Poder oferecer um produto de qualidade é outro fator colocado em questão, Santiago (2012) vai dizer que se uma empresa procura ser reconhecida por sua qualidade, deve estar disposta a pagar por esse diferencial e também divulgar com o mesmo nível de qualidade, para isso seria necessário verificar a fonte fornecedora de combustíveis e analisar se esse produto é realmente genuíno antes de comprá-lo através de certificações confiáveis, e posteriormente expor nas bombas abastecedoras, qual a distribuidora que forneceu o combustível, garantindo então a confiança dos clientes. De acordo com Hooley, Saunders e Piercy (2005), o intuito principal do marketing é deixar o cliente em primeiro plano, usando os co- nhecimentos e habilidades para alavancar as vantagens sobre a concorrência, uma vez que o cliente estiver plenamente satisfeito com o produto ofertado, sua fidelização será iminente.

Para diminuir os níveis de insatisfações que envolvem o processo de melhoria continua - tanto do produto, como o de serviço - nos postos de combustíveis seria necessária uma avaliação bem fundamentada envolvendo não só o marketing externo, como o interno também. Segundo Hooley, Saunders e Piercy (2005), o marketing interno é também uma das pontas de vantagem competitiva, sendo planejado como parte da estratégia competitiva e unificação de demais áreas das organizações para melhor aplicá-la. Para simplificar melhor, pode-se dizer que ajustar os processos internos que envolvem a administração da empresa, juntamente com a parte que está ligada diretamente ao público como por exemplo, os vendedores, cria uma harmonização dentro do ambiente empresarial, criando assim algumas pontes de chegada ao objetivo principal.

Elevar os preços de acordo com a concorrência pode ser uma maneira de estar igualado a eles, ao invés de se sobressair, Las Casas (2009), afirma que é preciso conhecer o concorrente e o preço do qual está ofertando para poder disputar no mercado. Isso indica que não é necessário estar idêntico, mas similarmente seria o suficiente. Os preços são a parte onde mais envolve diferenciação, uma vez que os clientes buscam sempre o lugar mais em conta para abastecer, não descartando a qualidade. Sujeita-se então que é preciso saber se o cliente estará disposto a pagar pelo preço do combustível ofertado, ou se irá buscar na concorrência algo mais relevante.

Criar uma vantagem competitiva envolve os elementos essenciais de uma organização, entre eles é possível enxergar o Mix de marketing, que de acordo com Zeithamll (2014), mostra os pontos chaves de uma estratégia, sendo este oferecendo um bom preço de acordo com o produto ofertado, estabilizar a localidade do negócio em uma área estrategicamente analisada, barganhar os valores com fornecedores e, inserir novos produtos ao mercado. Os 4P's que é como conhecido o Mix de marketing, será usado como uma ferramenta de vantagem competitiva de feito vantajoso nos objetivos organizacionais porque 
abrange o ambiente no qual está atuando, Segundo Silva e Batalha (2007) é uma forma de divulgar o produto, com um preço estabilizado em um ponto de distribuição/vendas planejado.

Assim, pode-se verificar que a dinâmica em torno das ações práticas para a eficácia do marketing como uma vantagem competitiva envolvem diversos benefícios, primeiramente na imagem da empresa transmitida ao consumidor, que aumentaria a credibilidade no mercado, o reconhecimento pela qualidade do combustível oferecido seria muito mais visado, com grandes indícios de fidelização da mesma. É evidente que todos esses fatores beneficiariam a organização não só como uma configuração sintética, mas principalmente de forma veridicamente comprovada. $O$ resultado posterior a essas ações seria o aumento dos indicadores financeiros, que é o principal motivo da existência da empresa. Lembrando que nenhum processo de melhoria é facilmente implementado, pode-se ressaltar algumas dificuldades a princípio, como a oposição dos funcionários em relação a mudanças comportamentais, ou até mesmo da concorrência em relação aos preços, podendo incentivá-los a buscar essa posição de diferenciação sendo continuamente um processo de conflito organizacionais.

A despeito das limitações da pesquisa, a primeira delas está relacionada à amostra analisada e seu caráter não probabilístico que impedem que os resultados gerados por essa pesquisa sejam generalizados para todo o segmento ou para todas as empresas e, a segunda, por se tratar de um caso único, não possibilita a comparação com outras empresas, a fim de identificar as convergências e divergências existentes.

\section{CONSIDERAÇÕES FINAIS}

Este trabalho teve por objetivo verificar a relação entre o marketing e a vantagem competitiva, para tal foi realizado um estudo de caso, com abordagem qualitativa por meio de entrevistas, na empresa Rede JPS, no setor de combustíveis. A revisão de literatura segundo Alves, Barboza e Rolon (2014), sugere que as estratégias de marketing são capazes de criar vantagem competitiva para a organização, sendo conjuntamente essenciais para a alavancagem de novas perspectivas iniciando-se desde a criação de um novo produto/serviço. No estudo do setor de combustíveis, nota-se que criar a fidelização dos clientes através de uma boa estratégia de marketing, não está diretamente ligado somente a imagem e sim ao valor agregado no produto, ou seja, oferecer algo de qualidade é totalmente vantajoso, mas agregar a ele um diferencial promove mais ainda a forças de vendas.

Os principais resultados demonstraram que embora dos objetivos tenham sido alcançados, não puderam ser colocados em pauta, pois diante a situação encontrou-se a dificuldade dos gestores ao aplicar as soluções apresentadas. Apesar de ter em mãos do porque o marketing ser uma ferramenta de vantagem competitiva e principalmente de demonstrar os benefícios obtidos ao utilizar o marketing como uma vantagem competitiva, não foram o suficiente para a gerência pois entendeu-se que levaria um tempo consideravelmente longo para esse tipo de aplicação de solução, faltando então criar um cronograma com estimativa de tempo e custos. Para essa situação Hooley, Saunders e Piercy (2005), dizem que o marketing opera em dois níveis organizacionais: o estratégico e operacional. No nível operacional os gerentes de marketing lidam com as tarefas do dia a dia, zelando pelo ambiente de trabalho que está ligado diretamente com o cliente, enquanto no nível estratégico o marketing atua como um auxiliar nas tomadas de decisões no mercado do qual está competindo, por isso que análise feita a respeito do que o cliente está a procura é extremamente importante. Para se criar vantagem competitiva através de competência, é necessário deixar o cliente em primeiro plano, usando os conhecimentos e habilidades como um coadjutor a fim de alcançar o que se espera. Sendo assim, nessa mesma linha de raciocínio avaliar o nicho do qual está se atuando, principalmente a fatores que se diz respeito a concorrência, devem ser levados em consideração, para criar novos pontos estratégicos.

A princípio, tinha-se receio de que o questionamento sobre os temas desta pesquisa não fosse bem compreendido pelos stakeholders durante a entrevista, porém foi surpreendente o entendimento deles quanto aos assuntos tratados, acreditando-se que isso se deve pela própria rede de informações que faz parte de seu cotidiano. Percebe-se então que os 
colaboradores reconhecem a necessidade de algumas mudanças, apontando uma melhoria por parte da própria força de trabalho voluntariamente, mas necessitaria de muita disposição por parte da gerência para ajudar os funcionários a desenvolverem essas características necessárias.

Diante do exposto as implicações mais relevantes são de natureza empírico/gerencial, pois durante a realização da pesquisa constatou-se a necessidade de colocar em prática o marketing como uma vantagem competitiva que são eixos empíricos e gerenciais mais condizentes com as necessidades expressas da organização no atual contexto da empresa. (FLEURY; FLEURY, 2001).
Como sugestão de estudos futuros é necessário ampliar a amostra para outras revisões de literatura, ampliar o período de tempo para possibilitar uma visão mais abrangente do emprego dos métodos de pesquisa, podendo apresentar contribuições significativas como, por exemplo, permitir novas contribuições metodológicas na área e ampliar a análise dos resultados e, por fim, a realização de futuras pesquisas ligando o objeto de pesquisa "Eficácia do marketing como vantagem competitiva" com as escolhas metodológicas que se mostrariam relevantes no sentido de verificar tendências e oportunidades de pesquisa, para que os profissionais e gestores da área tenham mais clareza sobre o tema. 


\section{REFERÊNCIAS}

ALMEIDA, M. S. Elaboração de projeto, TCC, dissertação e tese: uma abordagem simples, prática e objetiva. São Paulo: Atlas, 2011.

ALVES; BARBOZA; ROLON. Marketing ponto a ponto. Edição, 1. Ano, 2014, 288.

CERVO, A. L. Metodologia cientifica. 6. ed. São Paulo: Pearson Prentice Hall, 2007.

CHURCHILL, G. A.; PETER, J. P. Marketing: criando valores para os clientes. São Paulo: Saraiva, 2000.

COLLIS, J.; HUSSEY, R. Pesquisa em administração: um guia prático para alunos de graduação e pós-graduação. 2.ed. Porto Alegre: Bookman, 2005. $349 p$.

CRESWELL, J. W. Projeto de pesquisa: métodos qualitativos, quantitativos e misto. Porto Alegre: Artmed, 2010.

DRUCKER; GREENE; NEWTON. Coleção Harvard de administração. 6.ed. São Paulo: Nova cultural, 1986, 93.

FILHO, D. P. Metodologia cientifica. 6.ed. São Paulo: Futura, 1998.

FLEURY, M. T. L; FLEURY, A. Construindo o conceito de competência. RAC, edição especial 2001.

GIL, A. C. Como elaborar projetos de pesquisa. 4.ed. Atlas: São Paulo, Brasil, 2002.
HOOLEY; SAUNDERS; PIERCY. Estratégia de marketing e posicionamento competitivo. 3.ed. São Paulo-SP: Pearson Education do Brasil, 2005.

KOTLER; KELLER, L. Administração de marketing. Traduzindo por Mônica Rosenberg, Cláudia Freire, Brasil Ramos Fernandes. 12.ed. São Paulo: Prentice Hall, 2006.

KOWALKOWSKI, C. Dynamics of value propositions: insights from service-dominant logic. European Journal of Marketing, v. 45, n. 1/2, p. 277-294, 2011.

LAS CASAS, A. L. Marketing: Conceitos, exercícios e casos. São Paulo: Atlas, 2009.

MAGALHÃES; SAMPAIO. Planejamento de marketing: conhecer, decidir, agir. São Paulo: Pearson Prentice Hall, 2007, 14

MINTZBERG, H., LAMPEL, J., QUINN, J., GHOSHAL, S. O Processo da estratégia. Porto Alegre: Bookman, 2009.

SANTIAGO, Marcelo Piragibe. Gestão de marketing. 1.ed. Curitiba. Paraná. Rev: IESDE Brasil, 2012.

SILVA, A. L; BATALHA, M. O; Marketing estratégico aplicado ao agronegócio. In: BATALHA, M. O. (coord.). 3.ed. Gestão Agroindustrial. São Paulo: Atlas, 2007, v.1 p. 113 - 182.

ZEITHAML, V.; BITNER, M; GREMLER, D. Marketing de serviço. 6.ed. AMGH editora Ltda, 2014, 621. 